Patiño, Roxana. "Reseña de Vernacular Latin Americanisms. War, the Market, and the Making of a Discipline". Anclajes, vol. XXV, n. ${ }^{\circ}$ 2, mayo-agosto 202I, pp. 253-256.

https://doi.org/I0.19137/anclajes-202I-25216

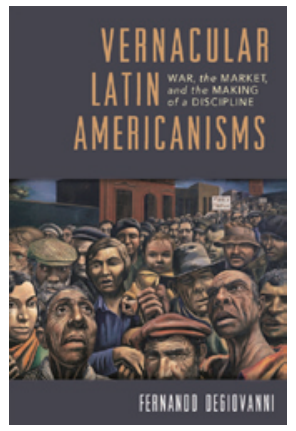

\title{
Reseña
}

anclajes

\author{
Vernacular Latin Americanisms. War, the \\ Market, and the Making of a Discipline \\ Fernando Degiovanni
}

Pittsburgh, University of Pittsburgh Press, 2018, 238 páginas.

$\mathrm{H}$ acerse preguntas al revés de la trama y las estructuras de los estudios consolidados de un campo del saber; intervenir esa extensa estantería del archivo disciplinario de los estudios literarios latinoamericanos e intersectarlo con ejes desplazados de su construcción ya secular, nunca han sido tareas dóciles y, por lo demás, entrañan una voluntad de indagación dotada tanto de pasión como de rigor que Fernando Degiovanni viene ejerciendo, a través de investigaciones de largo aliento, desde su libro anterior: Los textos de la patria. Nacionalismo, políticas culturales y canon en Argentina (2007).

Este nuevo libro ha supuesto un desafío mucho mayor en varios sentidos. Se trata del estudio de la formación de un campo disciplinario -el de los estudios literarios latinoamericanos y sus diversas nominaciones según el espacio geográfico desde el que se lo estudie- entre principios de siglo XX y los años 1960, pensado, interrogado, no solo dentro el propio campo sino desde la mirada interdisciplinaria y amplia, en el cruce de la historia literaria y de la institución literatura, la historia intelectual y política, y la crítica cultural, entre las principales perspectivas.

Esto le permite a Degiovanni abrir el espectro de preguntas, de actores y agenciamientos factibles de tener en cuenta para analizar la formación de un campo de estudios que a principios del siglo XX no tenía una demarcación precisa, y que no ha cesado desde entonces de interrogarse sobre sí mismo: su estatuto epistemológico, la formación de su corpus/canon, sus implicancias culturales y políticas. Un campo ampliado -el Latinoamericanismo- configurado en los discursos desde el difícil "entre-lugar" de una deseada articulación comunitaria regional, que se abre camino entre los pujantes relatos maestros de los nacionalismos e internacionalismos de las primeras décadas del siglo. Pero uno de los valiosos aportes de su estudio radica en que el autor no piensa esa constitución previsiblemente desde un solo lugar, el regional, sino como un campo de disputa a nivel 
transnacional desde los orígenes mismos y no a posteriori de las sucesivas internacionalizaciones de la cultura de la región. Estos "latinoamericanismos", en plural, conformados en un espacio de circulación entre América Latina, España y Estados Unidos, con agendas transatlánticas $\mathrm{y}$ también hemisféricas de sus intelectuales y sus instituciones, bien diferenciadas pero entrecruzadas, le posibilitan a Degiovanni construir un entramado disciplinar mucho más complejo y, ciertamente, en tensión. Los estudios literarios hispano/ latinoamericanos fueron configurados, en la hipótesis de Degiovanni, desde diversas coordenadas regionales y geopolíticas que se afectan entre sí con propósitos y estrategias muy diversas a las de la gran tradición del pensamiento del americanismo cultural en la línea de José Martí, José Enrique Rodó y José Vasconcelos, como emblemas del pensamiento fundacional del campo. Un desafío no menor, toda vez que esto le implicó lidiar con otras premisas que discuten la centralidad de esa tradición en un archivo, según el autor, "más reverenciado que analizado".

Degiovanni avanza en su indagación suspendiendo las certezas de la historia tal como está contada y trabaja con hipótesis nunca antes tenidas en cuenta de manera articulada entre textos y sujetos de mayor y menor relieve. ¿Qué pasaría si pusiéramos en relación esta masa de textos y prácticas con otras coordenadas cruciales para el futuro de América Latina, Estados Unidos e, incluso, España? ¿Cómo crear una comunidad regional y a partir de qué vertebraciones, de qué ejes axiales articular su literatura? Una palabra clave es "guerra" (desde la guerra de 1898 hasta la guerra fría); la otra es "mercado" (desde el mercado concreto al mercado de bienes simbólicos).

El autor arma entonces un trípode hermenéutico, Latinoamericanismo, guerra $y$ mercado, sobre el que monta una suerte de teodolito y desde su mira agudiza esa perspectiva triangulada. Lo que se ve desde la mira es un impresionante archivo, probablemente un contra-archivo, construido sobre una valiosísima cantidad y calidad de documentos: institucionales (universitarios, gubernamentales), comerciales y personales; epistolarios cruciales y otros aparentemente secundarios; libros de todo tipo: eruditos y de viajes, colecciones, manuales y antologías; imágenes y archivos periodísticos, datos tecnológicos y de negocios, estadísticas, etc., nunca antes puestos en relación. El teodolito mide principalmente distancias y relieves; en la distancia corrobora la extensión real de esta conformación y en el relieve encuentra los vasos comunicantes de esta nueva topografía. Ese paisaje triangulado ofrece al investigador una cantera que Degiovanni hila, da forma con maestría y ductilidad. Casi a la manera de una novela detectivesca trama una narrativa que lleva al lector a descubrir en la formación misma de esta disciplina las lógicas de integración regional/continental/transatlántica por fuera de los relatos convencionales, en clave de las estrategias geopolíticas generadas por los conflictos bélicos y los procesos del comercio transnacionalizado de la economía de mercado.

$\mathrm{Al}$ desechar una narrativa con intento abarcativo de todo este proceso, Degiovanni opta por armar siete historias del recorrido de intelectuales y académicos que intervinieron de distintos modos en este proceso, y prueban la contundencia de su argumentación. Nuevamente el teodolito registra la mirada triangular entrecruzada: en el relieve aparecen una serie de figuras protagónicas del Latinoamericanismo tradicional, pero observadas según esta nueva perspectiva, junto a figuras conocidas pero menos valoradas, mucho menos en la ubicación que le da el autor, y figuras en algunos casos casi desconocidas. Son, además, representantes de los tres orbes estudiados, 
América Latina, Estados Unidos y España, sosteniendo tres agendas también cruzadas: el Latinoamericanismo, el Hispanismo, y el Panamericanismo, respectivamente.

El itinerario de estos intelectuales -que puede ser leídos como una novela de viajes- incluye a Jeremiah Ford y Alfred Coester, Manuel Ugarte y Rufino Blanco Fombona, Federico de Onís y Américo Castro; Pedro Henríquez Ureña, Luis Alberto Sánchez y Enrique Anderson Imbert, y posee un hilo conductor que se sostiene toda vez que ese monumental archivo entra en funcionamiento y los vincula. Para armar este recorrido interpretativo y sostener este elenco de figuras mayores y menores, el autor tuvo que desmontar lo que él denominó la "gruesa pátina hagiográfica" que pesa sobre las principales figuras, y demostrar cuán fundamentales fueron otras figuras de la trastienda de la tradición disciplinar.

A los estadounidenses Jeremiah Ford y Alfred Coester, que ocupan los dos primeros capítulos del libro, Degiovanni los descubre, literalmente, al menos para el público latinoamericano. Es el caso de dos figuras de escasa producción en términos del aporte disciplinario pero de una actuación crucial para el establecimiento de ese campo de estudios inexistente hasta el momento en Estados Unidos. El autor demuestra cómo desde su privilegiada posición en la Universidad de Harvard, Ford advirtió la importancia estratégica de apoyar el naciente Panamericanismo, justo en la coyuntura del triunfo militar sobre España (1898), la reformulación de la doctrina Monroe y la apertura del Canal de Panamá (1914), por un lado, y el estadillo de la Gran Guerra en el mismo año, por otro. Guerra, geopolítica y nuevos mercados guían la convicción de Ford sobre la necesidad de establecer un nuevo campo especializado y revertir la sólida tendencia decimonónica de la academia norteamericana centrada en una discipli- na que estudiaba la literatura de España y sus colonias. Dentro de sus numerosos discípulos Alfred Coester se destacó por escribir Literary History of Spanish America (1916) la primera historia de la literatura hispanoamericana mucho antes de que esta fuera escrita en español. Degiovanni sigue la deriva de los esfuerzos de ambos, ligados principalmente a un ambicioso programa cultural y educativo por construir un nuevo campo disciplinario como eficaz mediador con las estrategias geopolíticas y comerciales de expansión de Estados Unidos en la región.

Los siguientes capítulos están destinados a los españoles Federico de Onís y Américo Castro, en los que Degiovanni analiza los esfuerzos de los académicos peninsulares por introducir y establecer la categoría y la estrategia de los "estudios hispánicos” en Estados Unidos y en América Latina como forma de responder a la política de reconquista cultural post 1898 y contrarrestar el impulso del Panamericanismo. La ideología cultural del "Hispanismo" advierte claramente el potencial del mercado académico norteamericano en la demanda para su proyecto pedagógico y esgrime una planificada estrategia de mercado que Degiovanni desgrana con minuciosidad para demostrar cómo libros, manuales, antologías y colecciones, instituciones y programas, estuvieron a su servicio. El viejo imperio supo cómo proveer al nuevo imperio en el intento de definición de su nueva agenda académica.

Los capítulos destinados a los latinoamericanos Pedro Henríquez Ureña, Luis Alberto Sánchez y Enrique Anderson Imbert requerirían por su riqueza y nuevas perspectivas una extensión imposible de exponer aquí. Valga resaltar solo un par de valiosos aportes para alimentar la expectativa del lector especializado: la relectura del trayecto, actuación y escritos de Henríquez Ureña en Estados Unidos en los 1940 en relación con la política y la economía 
panamericanista así como con la estrategia antinazi y pro-aliados en la región; y la revalorización de la tendencia latinoamericanista y antiimperialista generada por los reformistas del 1918, expandida entre los ańos 1920 y los 1930, y consolidada a nivel continental desde el APRA peruano que inaugura con Luis Alberto Sánchez y la primera historia de la literatura latinoamericana publicada en América Latina, los intentos de un nuevo campo disciplinario, con otro signo, en torno a la literatura de la región.

Es de esperar una pronta versión en español de este libro, tan riguroso y documentado como ameno en su lectura, que ancla los estudios literarios latinoamericanos en el corazón de las turbulencias políticas, económicas y culturales en las que se dirimió su derrotero. Un libro necesario que arriesga con libertad y argumenta con solidez, una escasa y feliz combinación en estos tiempos.

\section{Roxana Patiño}

FACULTAD DE FILOSOFÍA Y HUMANIDADES UNIVERSIDAD NACIONAL DE CÓRDOBA ARGENTINA ORCID: 0000-0003-2414-479X 